OPEN ACCESS

Edited by:

Carlos Albert Reck-Burneo,

Medical University of Vienna, Austria

Reviewed by:

Risto Rintala,

Helsinki Children's Hospital, Finland

Erik David Skarsgard,

British Columbia Children's Hospital,

Canada

*Correspondence:

Taiwo A. Lawal

taiwo.lawal@hotmail.com

Specialty section:

This article was submitted to

Pediatric Surgery,

a section of the journal

Frontiers in Surgery

Received: 27 December 2018

Accepted: 13 February 2019

Published: 05 March 2019

Citation:

Lawal TA (2019) Overview o Anorectal Malformations in Africa.

Front. Surg. 6:7.

doi: 10.3389/fsurg.2019.00007

\section{Overview of Anorectal Malformations in Africa}

\author{
Taiwo A. Lawal* \\ Division of Pediatric Surgery, Department of Surgery, University of Ibadan and University College Hospital, Ibadan, Nigeria
}

Anorectal malformation is one of the most common structural congenital malformations treated by pediatric surgeons globally. The outcome of care is largely dependent on the spectrum, clinical features, associated malformations, expertise of the surgeons, and available perioperative facilities. Africa has a large burden of unmet surgical needs in children, and as in other low resource settings, local pediatric surgeons are faced with different and challenging clinical scenarios, hence, adopt various measures to enable children with surgically correctable congenital malformations to survive. There are increasing collaborations between local surgeons and experts in other continents, which often involves surgeons traveling to Africa on missions or well-structured partnerships. It is highly beneficial for the physician who is interested in global-surgery to understand the terrain in low resource settings and prepare for possible changes in management plan. This review highlights the epidemiology, clinical presentation, treatment, and outcome of care of children with anorectal malformations in Africa and provides options adopted by pediatric surgeons working with limited resources.

Keywords: Africa, anorectal malformations, burden of diseases, low resource settings, neonatal intestinal obstruction

\section{INTRODUCTION}

Anorectal malformation (ARM) is a spectrum of structural congenital defects involving the anorectum and variable segments of the urogenital system in boys and girls (1). The malformations range from skin level defects such as rectoperineal fistulas to complex lesions such as persistent cloaca. The cause has not been fully elucidated but it is likely to be multifactorial and include genetic and environmental factors $(1,2)$. The prognosis of ARM is related to the complexity of the malformation. Some of the most complex malformations are not easily treatable by all practitioners since those types occur infrequently and may be best handled by experts who are more familiar with them (3).

The treatment options, often, are influenced by factors related to the clinical presentation and facilities available for the perioperative care of children with complex congenital malformations. The epidemiology, clinical presentation, course, and outcome of care of ARM in Africa may thus be different from what occurs in other regions, hence, this review, which aims to highlight those aspects of management of patients with the malformation on the continent and provide options adopted by pediatric surgeons working with limited resources.

\section{EPIDEMIOLOGY OF ANORECTAL MALFORMATIONS IN AFRICA}

Congenital malformations account for one third to two fifths of the operative workload of pediatric surgeons in typical major referral hospitals in Africa $(4,5)$. ARM is the commonest major structural 
congenital malformation presenting to general pediatric surgeons on the continent (5). ARM is also the leading congenital cause of intestinal obstruction in African children $(6,7)$. The treatment of children with ARM is a major aspect of the work of pediatric surgeons as colostomy for ARM and the definitive anorectoplasty or anoplasty are the commonest colorectal procedures they perform (3).

A true birth incidence of ARM is difficult to obtain because there are no formal birth registries in most parts of Africa and most reports in the literature are hospital based. The best available population based estimates are from South Africa where the incidence of ARM has been reported to range from 1.79/10,000 live births in the Western Cape Region to 3.26/10,000 live births on the West Coast (8). These figures are about the same as the incidence of 1 in 5,000 live births reported elsewhere (1).

There is a slight to moderate male preponderance in cases of ARM ranging from 55 to $71 \%$ according to majority of reports (8-14) but a few had shown the reverse (15-18), which could be due to loss of male neonates from delay in seeking care in the catchment areas of the hospitals concerned. Rectovestibular fistula is the predominant type of ARM seen in females representing $70-78 \%$ of the malformations in girls $(8,14,17,19-21)$.

In boys, the spectrum is slightly more varied across the continent. Imperforate anus without fistula was the predominant type seen in $31-42 \%$ of boys with ARM in Kenya $(14,22)$. On the other hand, ARM with rectourethral fistula predominates in boys in Nigeria (9), Cape Town in South Africa (20), Ethiopia (17), Uganda (21), and in Malawi (23). A major limitation encountered in comparing the spectrum of malformations in various publications is the use of different and inconsistent classification schemes by various authors. The adoption of the Krickenbeck consensus classification scheme (24) has resulted in less confusion about the terminologies since the classification is clinically oriented (25).

The presence of associated malformations in other systems is seen in $9-44 \%$ of patients in various series across the continent $(9,12,15,17-19,26)$. Those figures are lower than the expected and more widely documented proportion of $50-78 \%(27-30)$ of patients with ARM who have associated malformations. Conversely, in a recent review of 282 children at the Red Cross War Memorial Children's Hospital, Cape Town using a more robust evaluation method, 152 (69\%) children were reported to have associated malformations in other systems (20).

The lower incidence of associated malformations in most reports from Africa have been attributed to higher mortality in the neonatal period $(9,26)$, less accurate detection and possibly because some children with more lethal associated defects would never be seen at a hospital after birth at home and subsequent demise (26). Some patients may be lost to follow-up after initial colostomy including some that may die from consequences of undiagnosed and untreated associated malformations (15). It is therefore, not improbable that the incidence of associated malformations in African children with ARM will increase as neonatal survival improves and many children reach the stage where accurate evaluations can be made.

\section{CHALLENGES IN THE NEONATAL PERIOD}

Early management is recommended in the treatment of children with ARM in order to prevent sepsis and other morbidities related to intestinal obstruction (1). Neonatal intestinal obstruction is a major surgical emergency that requires optimal neonatal resuscitation facilities, surgical care and anesthetic support. Neonatal intestinal obstruction is responsible for $24-64 \%$ of neonatal surgical admissions in Africa (31-33). ARM is a major cause accounting for $57-67 \%$ of cases of neonatal intestinal obstruction $(31,32,34)$.

Most children with ARM and clinically significant intestinal obstruction will require neonatal intensive care unit (NICU) support. This is to ensure optimal control of hypothermia, fluid and electrolyte balance, parenteral nutrition and respiratory support. These NICU facilities are largely unavailable in many centers. A cross-sectional study of pediatric surgeons and surgical capacity in West Africa showed that only $51 \%$ of 37 (surveyed) hospitals had a NICU or general ICU facility (35). The situation is more critical in very low birth weight or extremely premature babies with ARM as well as in those with severe associated congenital malformations involving the cardiovascular or respiratory systems. In some situations, pediatric surgeons often resort to dilatation of perineal fistulas in male and female neonates or vestibular fistulas in female neonates with very low birth weights or that are extremely preterm to gain time and improve chances of survival $(25,36)$. Expansion of neonatal surgical support services has been advocated as a way of improving the outcome of care of children requiring neonatal surgical care (34).

\section{DELAY IN PRESENTATION AND TREATMENT}

Delay in presentation of patients with ARM leads to progression of neonatal intestinal obstruction (Figures 1,2), sepsis, aspiration pneumonia, intestinal perforation, and sometimes death (13, 17, 37-39). Adejuyigbe et al. (9) in a retrospective review of 86 patients managed on account of ARM at Ile Ife, Nigeria reported that $74(86.0 \%)$ presented after $24 \mathrm{~h}$ of birth. In that series, nearly $60 \%$ of the patients presented with gross abdominal distension and over one-quarter had associated vomiting (9). Govender and Wiersma (40) in a retrospective study of 273 patients who presented to a tertiary hospital over a period of 8 years reported that 158 (57.9\%) presented after $24 \mathrm{~h}$ of birth i.e., delayed. Similarly, $63 \%$ of 78 children treated for ARM at a major referral center in southwest Uganda presented after $48 \mathrm{~h}$ of birth (21).

Delayed presentation is worse among female children because there is still some fecal discharge through the vestibular fistula in most instances unlike in males where abdominal distension occurs over a few days in most patients with a rectourethral fistula $(12,36)$. Urosepsis with septicemia is also more likely in males and it is possible that some of the boys who are not 
identified early would have died before reaching health care 8 facilities (23).

Reports indicate that a large proportion, ranging from 25 to 94.8\% of childbirths in Africa take place outside the hospital

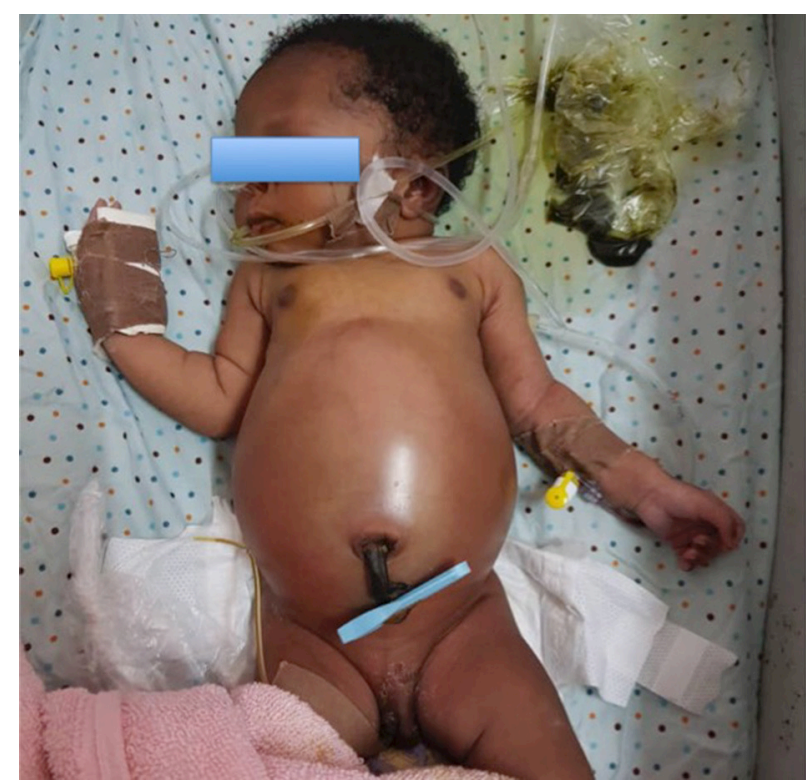

FIGURE 1 | A neonate brought to the hospital on the fourth day of life with intestinal obstruction secondary to anorectal malformation. environment (4, 41-46). A pediatrician, within a reasonable length of time after delivery, does not get to examine the majority of newborns as a result. Delivery outside a hospital setting is

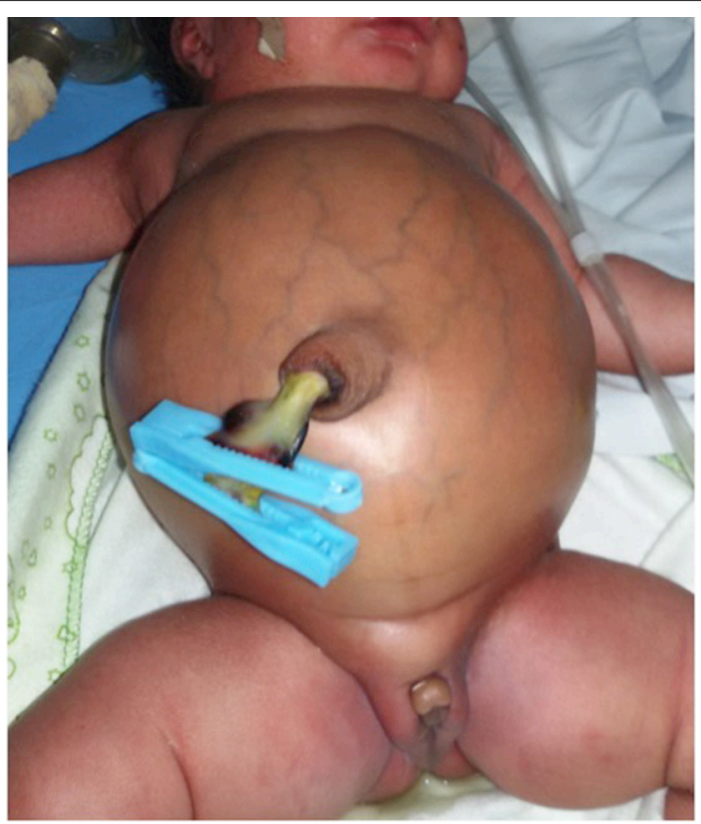

FIGURE 2 | A neonate with cloacal malformation and massive abdominal distension at presentation on the 8 day of life.

TABLE 1 | Timing and technique of definitive surgery for anorectal malformations in available publications across Africa.

\begin{tabular}{|c|c|c|c|c|c|}
\hline Publication & Country & $\begin{array}{l}\text { Technique for } \\
\text { "low" ARM }\end{array}$ & $\begin{array}{l}\text { Time of repair of } \\
\text { "low" ARM }\end{array}$ & $\begin{array}{l}\text { Technique for } \\
\text { "higher" ARM }\end{array}$ & $\begin{array}{l}\text { Time of repair of } \\
\text { "higher" ARM }\end{array}$ \\
\hline Shija (63) & Zimbabwe & $\begin{array}{l}\text { Cutback or } \\
\text { transfer anoplasty }\end{array}$ & At presentation & Abdominoperineal pull-through & $1-2$ years of age \\
\hline $\begin{array}{l}\text { Abdalla et al. } \\
(64)\end{array}$ & Egypt & & & PSARP & $\begin{array}{l}\text { Age: } 5 \text { months to } 8 \text { years (mean-23 } \\
\text { months). } \\
2 \text { months to } 3 \text { years after colostomy } \\
\text { (mean-9 months). }\end{array}$ \\
\hline $\begin{array}{l}\text { Kigo and } \\
\text { Ndung'u (22) }\end{array}$ & Kenya & PSARP & Not indicated & PSARP & $\begin{array}{l}10.9 \% \text { had definitive surgery by age of } 6 \\
\text { months; } 90.5 \% \text { waited for over } 6 \text { months } \\
\text { after colostomy }\end{array}$ \\
\hline $\begin{array}{l}\text { Archibong } \\
\text { and Idika (15) }\end{array}$ & Nigeria & Cut-back anoplasty & Not indicated & $\begin{array}{l}\text { Abdominosacroperineal } \\
\text { pull-through }\end{array}$ & Not indicated \\
\hline $\begin{array}{l}\text { Adejuyigbe } \\
\text { et al. (9) }\end{array}$ & Nigeria & Anoplasty & Neonatal period & $\begin{array}{l}\text { Sacroperineal pull-through \& } \\
\text { PSARP. }\end{array}$ & 4-12 months after colostomy \\
\hline Ntia et al. (65) & Nigeria & $\begin{array}{l}\text { Cut-back anoplasty, } \\
\text { perineal transplant }\end{array}$ & Neonatal period & PSARP & Not indicated \\
\hline $\begin{array}{l}\text { Beudeker } \\
\text { et al. (23) }\end{array}$ & Malawi & Anoplasty & Neonatal period & PSARP & Not indicated \\
\hline $\begin{array}{l}\text { Kuradusenge } \\
\text { et al. (14) }\end{array}$ & Kenya & Anoplasty & Neonatal period & PSARP \& ASARP & Mean of $211 \pm 111$ days \\
\hline $\begin{array}{l}\text { Gama and } \\
\text { Tadese (17) }\end{array}$ & Ethiopia & Anoplasty & Neonatal period & PSARP \& ASARP & Not indicated \\
\hline $\begin{array}{l}\text { Kayima et al. } \\
(21)\end{array}$ & Uganda & & & PSARP & Median age of 11 months \\
\hline $\begin{array}{l}\text { Mfinanga } \\
\text { et al. (18) }\end{array}$ & Tanzania & Anoplasty & Neonatal period & PSARP & Not indicated \\
\hline
\end{tabular}

ARM, anorectal malformation; ASARP, anterior sagittal anorectoplasty; PSARP, posterior sagittal anorectoplasty; NB, Studies focused on selected subset of patients were excluded. 
significantly associated with delayed diagnosis of ARM (40). It is sometimes up to the mothers and more experienced family members to identify children with gross structural anomalies (47). This is of course fraught with challenges, as most mothers had never heard of ARM (48). Furthermore, one out of every five mother, from a study conducted in Ibadan, Nigeria, was able to recognize babies with ARM (48). Delayed presentation has been largely attributed to delay in detection at birth, erroneous information given to parents, poor knowledge of birth defects, suboptimal treatment and socioeconomic factors $(12,49)$.

\section{PRESENTATION OUTSIDE THE NEONATAL PERIOD}

Presentation outside the neonatal period is widespread as 19$85 \%$ of patients with ARM in Africa present outside the first 4 weeks of life $(3,9,12,14,15)$. Delay in diagnosis has been correlated with poorer outcome and a higher mortality (9).

Patients with ARM sometimes present outside the neonatal period in other regions as well, but to a much less extent $(50,51)$. Delayed diagnosis beyond $24-48 \mathrm{~h}$ of birth is unusual in developed countries because of adherence to guidelines on newborn care since most deliveries are supervised. There may also be delay in diagnosis when the malformation is subtle or a rare variant such as H-type fistula is encountered $(52,53)$. Furthermore, extreme delays beyond childhood are uncommon except in low resource settings such as in many developing countries.

It is not unusual to see patients present well outside infancy in Africa (12, 54). Ogundoyin et al. (54) reported a 25-year-old Nigerian woman with ARM and rectovestibular fistula who then underwent a successful repair after an initial colostomy. Other authors have reported series with patients well outside of infancy and sometimes in adolescence $(9,12,55)$. Furthermore, when patients present early enough for treatment, there are tertiary level delays in intervention and the median time to emergency surgery may be as high as seven days as reported in a study that reviewed the pediatric surgical capacity in Africa (56). This delay is as a result of inadequate systemic support for pediatric surgical services, which often requires a multidisciplinary form of care and is human capita intensive $(56,57)$.

\section{SURGICAL AND PERIOPERATIVE CONSIDERATIONS}

The perioperative care of patients with ARM typifies the advancement of multidisciplinary care. Multidisciplinary approach has been shown to result in more optimal care of patients with ARM (58). Outside of Northern and Southern Africa and a few countries in Western Africa, many hospitals do not have a good complement of personnel to form multidisciplinary teams and the pediatric surgeon has to work with minimal resources and perform multiple roles, including training other staffs, to ensure that children with surgical conditions are given a chance to survive $(57,59-61)$.
There is a wide variation in the timing of the definitive procedure based on a multiplicity of factors that are general, i.e., globally relevant, and those that are specific to the region. General factors include the type of malformation, associated congenital malformations, expertise of the surgeon and availability of related specialists. Factors that are specific to the timing of definitive surgery on the continent include economic considerations for funding of surgery, imaging facilities, availability of experts skilled in neonatal anesthesia, and support facilities such as parenteral nutrition and neonatal intensive care $(13,14,23,62)$.

Table 1 illustrates the timing of definitive surgery for ARM in reports across Africa.

In view of the aforementioned challenges, most patients with ARM, other than rectoperineal fistulas, will have a diverting colostomy at presentation. The initial colostomy is life saving and done as an emergency procedure; it is not unusual that this procedure may be performed by a non-pediatric surgeon or nonsurgeon (36). It is important that most physicians practicing in the continent, especially in remote rural areas, are able to perform colostomy in neonates (41).

The colostomy of choice in the treatment of children with ARM is a divided distal descending/sigmoid colostomy (Figure 3) (66). Transverse colostomy, although faster and easier to construct, is generally not optimal except in extremely few patients with cloaca malformations that may benefit from vaginal replacement with the sigmoid colon (66). It was popular when there were relatively very few pediatric surgeons thus general practitioners and general surgeons constructed most colostomies (22). Transverse colostomy is less favored in the management of children with ARM because of the long length and surface of colon that could be in contact with the urinary tract through the fistula. It is also more difficult to clean out, it makes the high-pressure distal colostogram quite challenging to perform or interpret and has a high tendency to prolapse $(36,66$, 67). On the other hand, a divided distal descending/sigmoid colostomy ensures adequate fecal diversion and provides a better opportunity to do a high-pressure distal colostogram.

A divided distal descending/sigmoid colostomy is increasingly being performed for fecal diversion in the management of patients with ARM (67-69). An historical comparison of the

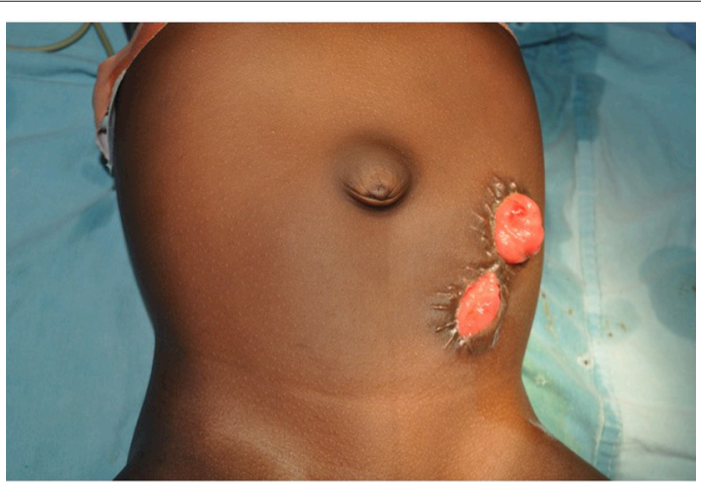

FIGURE 3 | A divided distal descending/sigmoid colostomy in a girl with anorectal malformation. 
management of children with ARM over two decades in Zaria, Nigeria showed that 69 patients who required a colostomy in the first 10 years (January 1988 to December 1997) of the review had transverse loop colostomy compared to 96 patients in the latter 10 years (January 1998 to December 2007) who had divided sigmoid colostomy (13). Loop colostomies are also not advisable in patients with ARM, because they may allow spillage into the distal limb with the possibility of recurrent urinary tract infections (66) and they are more likely to prolapse (70). A persistent concern though is the inadequate number of pediatric surgeons on the continent, especially in rural towns $(59,61)$, with $0.06-2.6$ pediatric surgeons per million population under 14 years $(57,60,61)$. The result is that there remains a high unmet surgical need in children especially in sub-Saharan Africa (71-73).

Colostomy for ARM may be associated with complications in 12.9-78.9\% (Table 2) of African children (14, 18, 68, 69, 74). The most commonly reported complications following colostomy for ARM are prolapse, skin excoriations and hemorrhage (Table 2). Colostomy prolapse may occur because of the use of highly mobile segment of the colon such as the transverse colon or siting a loop sigmoid colostomy rather than the recommended divided distal descending/sigmoid colostomy (36, 66, 67). Skin excoriations are rather much commoner than seen elsewhere (66, $75,76)$. This may not be unconnected with the non-availability or non-affordability of appropriate stoma bags for children in some countries $(69,74,77)$. Local surgeons have adapted the use of pieces of absorbent clothing material or improvised bags to collect the feces $(69,78)$. The use of such materials allow feces to stay in contact with the skin for long periods of time, which provides a milieu for maceration of the skin, infection and enzymatic auto-digestion of the macerated skin (77). Zinc oxide powder and/or petroleum jelly based ointments have been applied on the skin that will be in contact with feces to reduce the occurrence as well as to treat this complication $(74,77)$. The reported mortality rate after colostomy for ARM range from 0 to 25.4\% (Table 2) (9, 18, 68, 69, 74).

Anesthesia in the neonatal period is necessary for the procedures of diverting colostomy for rectourethral fistulas in boys, rectovestibular fistulas and cloaca malformations in girls as well as definitive anoplasty for rectoperineal fistulas. This is however, not always available. In some hospitals, non-physician anesthetic personnel are involved in anesthetizing children and are limited in the scope of their work (79). There are safety issues involved since these personnel are not fully trained in neonatal physiology and pharmacology necessary to have a full grasp of the surgical and anesthetic concerns of a surgical

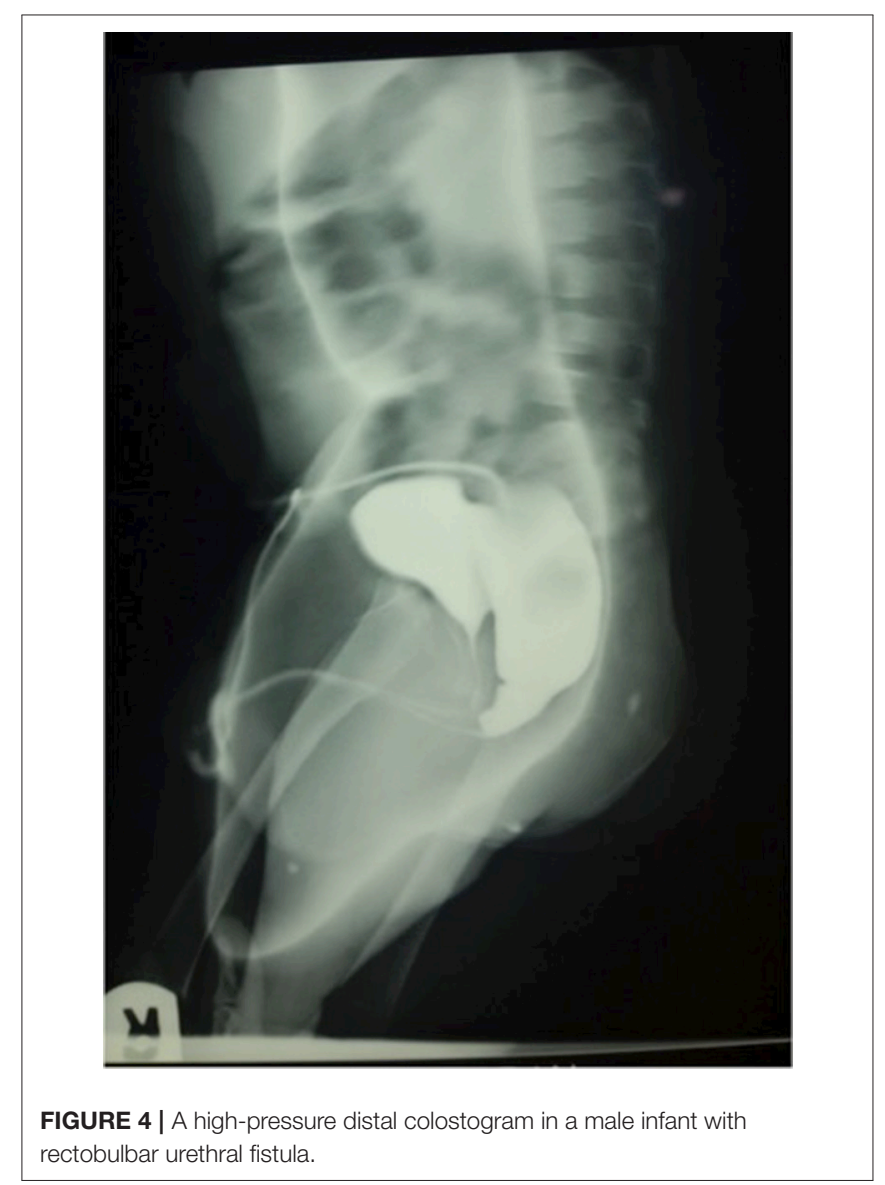

TABLE 2 | Common complications following colostomy for patients with anorectal malformations.

\begin{tabular}{|c|c|c|c|c|c|c|}
\hline Publication & Number who had colostomy & Number with complications (\%) & Prolapse & Bleeding & Skin excoriation & Mortality no (\%) \\
\hline $\begin{array}{l}\text { Adejuyigbe } \\
\text { et al. (9) }\end{array}$ & 59 & NA & NA & NA & NA & $15(25.4)$ \\
\hline $\begin{array}{l}\text { Chirdan et al. } \\
(68)\end{array}$ & 61 & $16^{\star}(26.2)$ & 3 & 2 & NA & $12(19.7)$ \\
\hline $\begin{array}{l}\text { Lukong et al. } \\
\text { (69) }\end{array}$ & 38 & $7(18.4)$ & 0 & 0 & 2 & $2(5.3)$ \\
\hline $\begin{array}{l}\text { Kuradusenge } \\
\text { et al. (14) }\end{array}$ & 31 & $4(12.9)$ & 1 & 0 & NA & NA \\
\hline $\begin{array}{l}\text { Aiwanlehi } \\
\text { et al. (74) }\end{array}$ & 19 & $15(78.9)$ & 4 & 3 & 15 & $0(0)$ \\
\hline $\begin{array}{l}\text { Mfinanga } \\
\text { et al. (18) }\end{array}$ & 107 & $34(31.8)$ & 11 & 5 & 8 & $8(7.5)$ \\
\hline
\end{tabular}

NA, information not available in the publication. ${ }^{\star} 12$ patients had superficial surgical site infections. NB, Studies limited to patients who had colostomy for anorectal malformations. 
neonate. Where facilities for general anesthesia in children are available, inadequate support services such as monitoring under anesthesia has been shown to lead to poorer outcomes in infants, children undergoing emergency surgery and American Society of Anesthesiologists (ASA) score of three or higher (80). Anesthetic considerations are quite important considering that $44 \%$ of emergency neonatal surgical interventions are as a result of ARM (34).

General anesthesia for neonates may not be available, safe or feasible and in some instances, local anesthesia is used $(68,69)$ but this is less than optimal because of the difficulty with examination of the peritoneal cavity, washing out of the distal colon and lack of abdominal wall relaxation. In addition to the availability of personnel and equipment, another factor that may determine the type of anesthetic used is the infant's general condition at operation; with low birth weight, premature or unstable infants more likely to undergo procedures under local anesthesia. In a comparison of two groups of neonates (one with weight $<2.5 \mathrm{~kg}$ and the other of weight $>2.5 \mathrm{~kg}$ at presentation) who had colostomy for ARM, 18/23 (78.3\%) in the first group compared to $20 / 38$ (52.6\%) in the second group had the surgery under local anesthesia (68). Where neonatal intensive care facilities or support services are absent, local anesthesia combined with oxygen supplementation via nasal catheter has helped to lower the mortality and will likely continue to be used in some children in low resource settings $(68,69,81)$. In some countries, there has been improvement in anesthetic facilities for neonates and an increasing number of neonates are offered general anesthesia even by non-physician anesthetists, especially nurse anesthetists $(34,82)$.

Imaging support is crucial in the care of patients with ARM (83). This includes abdominal and pelvic ultrasound scans to evaluate associated urinary and reproductive tract malformations shortly after birth, cross table lateral radiograph to classify the malformation and a high pressure distal colostogram (Figure 4) to define the specific type of rectourethral fistula in boys $(1,25,83,84)$. Others include radiographs to prognosticate the condition and magnetic resonance imaging (and ultrasound scan) to define the anatomy, screen for tethered cord and evaluate for other associated malformations $(25,83-$ 86). While basic imaging is available in many centers, many patients will not benefit from some important evaluations because of absence of facilities, lack of radiologist, lack of fluoroscopy guidance or economic considerations (87). The more widespread nature of ultrasonographic facilities has

TABLE 3 | Complications following definitive surgery for patients with anorectal malformations in published series from Africa.

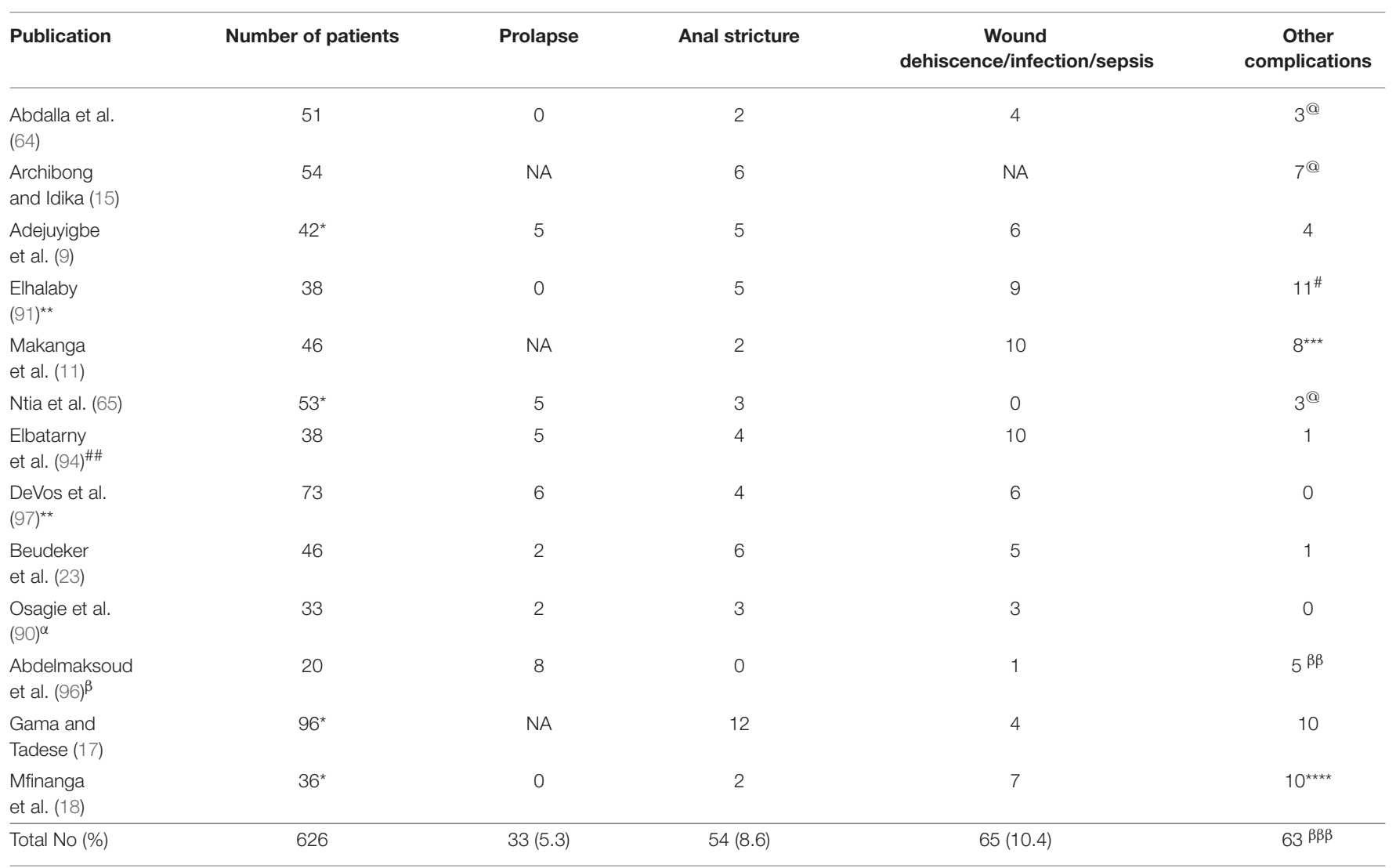

NA, information not available in the publication. @ Fecal incontinence. *These were the patients who had definitive surgery among the patients reported in the series. ${ }^{* *}$ Patients in this report had high or intermediate malformations. \#Six patients had injury to the posterior vaginal wall. ${ }^{\star \star \star}$ Six patients died. \#\# Single stage approach used. $\alpha$ Patients had high malformations only. ${ }^{\beta}$ Study limited to laparoscopy assisted anorectal pull-through in boys. ${ }^{\beta \beta}$ Three patients re-operated for retraction and mislocation. ${ }^{* * \star}$ Seven patients died. ${ }^{\beta \beta \beta}$ Highly variable as some series did not comment on incontinence as a complication and some did not report mortality rate after definitive surgery. 
been suggested as a way forward in regions with limited resources (36). Perineal ultrasound can be used as an adjunct to estimate the distance between the rectal pouch and the skin $(36,87)$.

At many of the pediatric surgical centers in Africa, definitive surgery for most malformations, other than perineal fistulas, is done outside the neonatal period $(67,88)$. More recently, some centers are performing primary definitive surgery for ARM in the neonatal period. Osifo et al. $(89,90)$ performed a primary Posterior Sagittal Anorectoplasty (PSARP) in five well-selected patients with rectovestibular fistula, rectourethral fistula and ARM without fistula. All five patients were operated between the second and seventh days of life and were discharged home between eight and ten days after surgery. Elhalaby in Egypt (91) and Adeniran et al. (92) in Ilorin, Nigeria had also demonstrated the feasibility of primary PSARP without colostomy in carefully well-selected males with "intermediate" types of malformations. Others have also performed primary PSARP for girls with rectovestibular fistulas $(13,91,93)$. It is to be noted, however that experienced surgeons practicing in centers with good neonatal perioperative support did those and the rate of wound infection, which may be as high as $26.3 \%$ (94) may be quite a challenge to manage in most hospitals (91). Thus, most pediatric surgeons, even in countries with good support facilities, will recommend staged approach for boys with ARM apart from those with perineal fistulas $(67,88)$.

The most commonly adopted technique for perineal fistula is anoplasty and for "higher lesions" is a PSARP (Table 1). The PSARP technique, as popularized by Peña and Devries (95) is easy to teach and adopt and follows anatomical landmarks. The procedure involves identification of the distal rectum, separation and ligation of any fistula, mobilization of the rectum, and placing it within the muscle complex and parasagittal fibers of the external sphincter (95). There is a need for intraoperative muscle stimulation to identify where to place the distal rectum. Improper localization may lead to fecal incontinence and the need for a reoperation. While a few centers have the Peña muscle stimulator for this purpose (64), most hospitals lack this facility and therefore improvise with various forms of nerve stimulators $(36,96)$. Others use regular electrocautery but this is more likely to be successful if the sphincter muscles are fairly well-developed (36). Other approaches to definitive surgery include the anterior sagittal anorectoplasty (ASARP), which aims to preserve the internal sphincter and is sometimes used for females with rectovestibular fistulas (14, 17). Sacroperineal and abdomino-sacroperineal pull-throughs were practiced in the past $(9,15)$ but not reported in recent series (Table 1). Laparoscopy assisted anorectal pull-through (LAARP) is feasible, but is largely limited to Egypt and South Africa $(96,97)$.

\section{SPECIAL CONSIDERATIONS IN MANAGEMENT}

The prognosis following management of patients with ARM on the continent mirror what is reported for the various malformations in the literature (1). A major challenge though remains continuity of care as only a few series had reported excellent long-term follow up periods. The reasons for this may be multifactorial and include accessibility to subsequent care, nomadic population and migration, parents not wanting the child because of erroneous beliefs about the malformation etc. $(9,15,71,98)$.

Rectovesical fistulas in boys are associated with the worst prognosis for bowel control while perineal fistulas have the best prognosis $(1,9,18,22,90)$. In a study evaluating long term outcome in patients who had surgery for ARM in Kenya, voluntary bowel movement was reported among $79.1 \%$ of boys and $75 \%$ of girls with perineal fistula, $76 \%$ of girls with vestibular fistula, $73.9 \%$ of boys with rectourethral fistula and $12.5 \%$ of boys with rectovesical fistula (22). Similarly, 33 of 37 patients (89.2\%) available for long-term follow-up in Ile Ife, Nigeria had "good outcome"; with occasional soiling in four and incontinence in one patient (9). Others also reported similar outcome with "good bowel motion" or fecal continence in 62.5-90.1\% $(21,64,65)$ following surgery for children with ARM. In addition, prognosis for continence tends to be better in children who had surgical interventions earlier than later $(18,22)$.

Following definitive surgery, complications are reported among one third of the patients (Table 3) although actual figures may be higher in some series as patients may be lost to follow up and some of those may die (15). The most prevalent complications (Table 3) are wound infection and or sepsis with or without wound dehiscence (10.4\%), anal strictures (8.6\%), and prolapse (5.3\%). Septic complications can occur after surgery for "low," "intermediate," or "high" malformations. Staged approach, for all malformations, other than perineal fistulas, is highly recommended to reduce septic complications $(9,11,36,91)$.

Skin level anal stricture, is a major preventable complication after definitive surgery, and has been reported in 5-14\% of patients $(9,13,15,90,91)$. This complication was seen after surgery in as much as $49 \%$ of patients before the adoption of PSARP as the approach for definitive surgery (13). Skin level anal stricture is due to failure of compliance with anal dilation regimen while deeper and more fibrotic stricture occurs because of vascular injury during handling and mobilization of the distal rectal stump (99). The majority of cases of anal strictures are amenable to anal dilatation. An option that has been adopted is to make the initial anoplasty wider than usual in older patients with larger rectal pouches and those that are likely difficult to follow up in the hospital (36).

The overall mortality in children with ARM range from 4.3 to $31.0 \%(9,14,18,21,63,65)$. The mortality rate is higher in children with associated malformations $(9,14)$, those with "higher" malformations (11) and in the neonatal period (9). The commonest causes of death are associated malformations and sepsis $(9,14)$.

\section{CONCLUSION}

Anorectal malformations account for a major part of the workload of pediatric surgeons practicing in Africa; the 
epidemiology, clinical features and preoperative work-up are quite varied but delayed presentation is usual, especially in sub-Saharan Africa. A huge challenge in management is the inadequate number of pediatric surgeons or support services and facilities to care for these children especially in the neonatal period. The outcome of surgery is dependent on the specific type of malformation but is better when intervention is commenced early. Early diagnosis, improvement in neonatal

\section{REFERENCES}

1. Levitt MA, Pena A. Anorectal malformations. Orphanet J Rare Dis. (2007) 2:33. doi: 10.1186/1750-1172-2-33

2. Wijers CH, de Blaauw I, Marcelis CL, Wijnen RM, Brunner H, Midrio P, et al. Research perspectives in the etiology of congenital anorectal malformations using data of the International Consortium on Anorectal Malformations: evidence for risk factors across different populations. Pediatr Surg Int. (2010) 26:1093-9. doi: 10.1007/s00383-010-2688-0

3. Lawal TA, Olulana DI, Ogundoyin OO. Spectrum of colorectal surgery operations performed in a single paediatric surgery unit in sub-Saharan Africa. Afr J Paediatr Surg. (2014) 11:128-31. doi: 10.4103/0189-67 25.132802

4. Ameh E, Chirdan L. Paediatric surgery in the rural setting: prospect and feasibility. West Afr J Med. (2001) 20:52-5.

5. Lawal TA, Adeleye AO, Ayede AI, Ogundoyin OO, Olulana DI, Olusanya AA, et al. Congenital paediatric surgical cases in Ibadan: patterns and associated malformations. Afr J Med Med Sci. (2017) 46:49-55.

6. Ameh EA, Chirdan LB. Neonatal intestinal obstruction in Zaria, Nigeria. East Afr Med J. (2000) 77:510-3.

7. Ogundoyin OO, Afolabi AO, Ogunlana DI, Lawal TA, Yifieyeh AC. Pattern and outcome of childhood intestinal obstruction at a tertiary hospital in Nigeria. Afr Health Sci. (2009) 9:170-3.

8. Theron A, Numanoglu A. Birth prevalence of anorectal malformations for the western cape province, South Africa, 2005 to 2012. Eur J Pediatr Surg. (2017) 27:449-54. doi: 10.1055/s-0036-1597945

9. Adejuyigbe O, Abubakar AM, Sowande OA, Olayinka OS, Uba AF. Experience with anorectal malformations in Ile-Ife, Nigeria. Pediatr Surg Int. (2004) 20:855-8. doi: 10.1007/s00383-004-1297-1

10. Hesse A, Appeadu-Mensah W. Anorectal Anomalies in Ghana-a review of 54 Cases. Afr J Paediatr Surg. (2006) 3:4-8.

11. Makanga M, Ntirenganya F, Kakande I. Anorectal malformations at University teaching hospital of butare in Rwanda: a review of 46 operative cases. East Central Afr J Surg. (2007) 12:110-5.

12. Eltayeb AA. Delayed presentation of anorectal malformations: the possible associated morbidity and mortality. Pediatr Surg Int. (2010) 26:801-6. doi: 10.1007/s00383-010-2641-2

13. Lukong CS, Ameh EA, Mshelbwala PM, Jabo BA, Gomna A, Akiniyi OT, et al. Management of anorectal malformation: changing trend over two decades in Zaria, Nigeria. Afr J Paediatr Surg. (2011) 8:19-22. doi: 10.4103/0189-6725.78663

14. Kuradusenge P, Kuremu RT, Jumbi G, Saula PW. Pattern of anorectal malformations and early outcomes of management at moi teaching and referral hospital Eldoret-Kenya. East Afr Med J. (2014) 91:430-4.

15. Archibong A, Idika I. Results of treatment in children with anorectal malformations in Calabar, Nigeria. South Afr J Surg. (2004) 42, 88-90.

16. Sowande $\mathrm{O}$, Adejuyigbe $\mathrm{O}$, Alatise $\mathrm{O}$, Usang $\mathrm{U}$. Early results of the posterior saggital anorectoplasty in the treatment of anorectal malformations in Nigerian children. J Ind Assoc Pediatr Surg. (2006) 11:85. doi: 10.4103/0971-9261.25930

17. Gama M, Tadesse A. Management of anorectal malformation: experience from ethiopia. Ann Afr Surg. 15, 25-28. doi: 10.4314/aas.v15i1.6

18. Mfinanga RJ, Massenga A, Mashuda F, Gilyoma JM, Chalya PL. Clinical profile and outcome of surgical management of anorectal malformations at a tertiary care hospital in Tanzania. Tanzania J Health Res. (2018) 20, 1-11. doi: 10.4314 /thrb.v20i1.4 intensive care support, especially for children with associated malformations in other systems, and prevention of sepsis will help reduce the mortality rate.

\section{AUTHOR CONTRIBUTIONS}

The author confirms being the sole contributor of this work and has approved it for publication.

19. Moore SW, Sidler D, Hadley GP. Anorectal malformations in Africa. S Afr J Surg. (2005) 43:174-5

20. vd Merwe E, Cox S, Numanoglu A. Anorectal malformations, associated congenital anomalies and their investigation in a South African setting. Pediatr Surg Int. (2017) 33:875-82. doi: 10.1007/s00383-017-4109-0

21. Kayima P, Kitya D, Punchak M, Anderson GA, Situma M. Patterns and treatment outcomes of anorectal malformations in Mbarara Regional Referral Hospital, Uganda. J Pediatr Surg. (2018). doi: 10.1016/j.jpedsurg.2018. 07.019. [Epub ahead of print].

22. Kigo C, Ndung'u J. Bowel function following primary repair of anorectal malformations at Kenyatta National Hospital. East Afr Med J. (2002) 79:124-7. doi: 10.4314/eamj.v79i3.8889

23. Beudeker N, Broadis E, Borgstein E, Heij HA. The hidden mortality of imperforate anus. Afr J Paediatr Surg. (2013) 10:302. doi: 10.4103/0189-6725.125417

24. Holschneider A, Hutson J, Peña A, Beket E, Chatterjee S, Coran $A$, et al. Preliminary report on the International Conference for the Development of Standards for the Treatment of Anorectal Malformations. J Pediatr Surg. (2005) 40:1521-6. doi: 10.1016/j.jpedsurg.2005. 08.002

25. Van der Steeg H, Schmiedeke E, Bagolan P, Broens P, Demirogullari B, Garcia-Vazquez A, et al. European consensus meeting of ARM-Net members concerning diagnosis and early management of newborns with anorectal malformations. Techn Coloproctol. (2015) 19:181-5. doi: 10.1007/s10151-015-1267-8

26. Moore S, Alexander A, Sidler D, Alves J, Hadley G, Numanoglu A, et al. The spectrum of anorectal malformations in Africa. Pediatr Surg Int. (2008) 24:677-83. doi: 10.1007/s00383-008-2131-y

27. Rintala RJ. Congenital anorectal malformations: anything new? J Pediatr Gastroenterol Nutr. (2009) 48(Suppl. 2):S79-82. doi: 10.1097/MPG.0b013e3181a15b5e

28. Nah SA, Ong CC, Lakshmi NK, Yap TL, Jacobsen AS, Low Y. Anomalies associated with anorectal malformations according to the Krickenbeck anatomic classification. J Pediatr Surg. (2012) 47:2273-8. doi: 10.1016/j.jpedsurg.2012.09.017

29. Bãlãnescu R, Topor L, Moga A. Anomalies associated with anorectal malformations. Chirurgia. (2013) 108:38-42.

30. Stoll C, Dott B, Alembik Y, Roth MP. Associated anomalies in cases with anorectal anomalies. Am J Med Genet A. (2018) 176:2646-60. doi: 10.1002/ajmg.a.40530

31. Tenge-Kuremu R, Kituyi P, Tenge C, Kerubo J. Neonatal surgical emergencies at moi teaching and referral hospital in Eldoret-Kenya. East Central Afr J Surg. (2007) 12:36-9.

32. Ademuyiwa A, Sowande O, Ijaduola T, Adejuyigbe O. Determinants of mortality in neonatal intestinal obstruction in Ile Ife, Nigeria. Afr J Paediatr Surg. (2009) 6:11. doi: 10.4103/0189-6725.48568

33. Mohammed M, Amezene T, Tamirat M. Intestinal obstruction in early neonatal period: A 3-year review of admitted cases from a tertiary hospital in ethiopia. Ethiop J Health Sci. (2017) 27:393-400. doi: 10.4314/ejhs.v27i4.10

34. Ameh EA, Seyi-Olajide JO, Sholadoye TT. Neonatal surgical care: a review of the burden, progress and challenges in sub-Saharan Africa. Paediatr Int Child Health. (2015) 35:243-51. doi: 10.1179/2046905515Y.00000 00033

35. Okoye MT, Ameh EA, Kushner AL, Nwomeh BC. A pilot survey of pediatric surgical capacity in West Africa. World J Surg. (2015) 39:669-76. doi: $10.1007 / \mathrm{s} 00268-014-2868-5$ 
36. Poenaru D, Borgstein E, Numanoglu A, Azzie G. Caring for children with colorectal disease in the context of limited resources. Semin Pediatr Surg. (2010) 19:118-27. doi: 10.1053/j.sempedsurg.2009.11.017

37. Tong W-D, Ludwig KA. Neonatal colon perforation due to anorectal malformations: can it be avoided? World J Gastroenterol. (2013) 19:3915. doi: 10.3748/wjg.v19.i25.3915

38. Eltayeb AA. Anorectal malformations presenting with colorectal perforation: frequency, associated morbidity and mortality. Surg Prac. (2014) 18:23-6. doi: 10.1111/1744-1633.12044

39. Olatunji T, Igoche M, Anyanwu P, Ameh EA. Spontaneous ileal perforation complicating low anorectal malformation. Afr J Paediatr Surg. (2015) 12:152. doi: 10.4103/0189-6725.160411

40. Govender S, Wiersma R. Delayed diagnosis of anorectal malformations (ARM): causes and consequences in a resource-constrained environment. Pediatr Surg Int. (2016) 32:369-75. doi: 10.1007/s00383-01 6-3866-5

41. Ameh EA, Dogo PM, Nmadu PT. Emergency neonatal surgery in a developing country. Pediatr Surg Int. (2001) 17:448-51. doi: 10.1007/s0038300 00551

42. Magoma M, Requejo J, Campbell OM, Cousens S, Filippi V. High ANC coverage and low skilled attendance in a rural Tanzanian district: a case for implementing a birth plan intervention. BMC Pregnancy Childbirth. (2010) 10:13. doi: 10.1186/1471-2393-10-13

43. Desalegn E, Mekonnen A, Abeje G. Place of delivery after antenatal care: the case of Fogera district, Amhara region, North West, Ethiopia; 2013. J Gynecol Obstetr. (2014) 2:1-6. doi: 10.11648/j.jgo.20140201.11

44. Nduka I, Nduka E. Determinants of noninstitutional deliveries in an urban community in Nigeria. J Med Invest Prac. (2014) 9:102. doi: $10.4103 / 9783-1230.144770$

45. Anastasi E, Borchert M, Campbell OM, Sondorp E, Kaducu F, Hill O, et al. Losing women along the path to safe motherhood: why is there such a gap between women's use of antenatal care and skilled birth attendance? A mixed methods study in northern Uganda. BMC Pregnancy Childbirth. (2015) 15:287. doi: 10.1186/s12884-015-0695-9

46. Kasaye HK, Endale ZM, Gudayu TW, Desta MS. Home delivery among antenatal care booked women in their last pregnancy and associated factors: community-based cross sectional study in Debremarkos town, North West Ethiopia, January 2016. BMC Pregnancy Childbirth. (2017) 17:225. doi: 10.1186/s12884-017-1409-2

47. Pilkington M, Situma M, Winthrop A, Poenaru D. Quantifying delays and self-identified barriers to timely access to pediatric surgery at Mbarara Regional Referral Hospital, Uganda. J Pediatr Surg. (2018) 53:1073-9. doi: 10.1016/j.jpedsurg.2018.02.045

48. Lawal TA, Fatiregun AA, Yusuf OB. Mothers' awareness of anorectal malformations: a pointer to delayed diagnosis in a developing country. Eur J Pediatr Surg. (2013) 23:480-5. doi: 10.1055/s-0033-1337116

49. Lawal TA, Yusuf B, Fatiregun AA. Knowledge of birth defects among nursing mothers in a developing country. Afr Health Sci. (2015) 15:180-7. doi: 10.4314/ahs.v15i1.24

50. Lindley RM, Shawis RN, Roberts JP. Delays in the diagnosis of anorectal malformations are common and significantly increase serious early complications. Acta Paediatr. (2006) 95:364-8. doi: 10.1080/08035250500437523

51. Turowski C, Dingemann J, Gillick J. Delayed diagnosis of imperforate anus: an unacceptable morbidity. Pediatr Surg Int. (2010) 26:1083-6. doi: 10.1007/s00383-010-2691-5

52. Lawal TA, Chatoorgoon K, Bischoff A, Peña A, Levitt MA. Management of H-type rectovestibular and rectovaginal fistulas. J Pediatr Surg. (2011) 46:1226-30. doi: 10.1016/j.jpedsurg.2011.03.058

53. Lawal TA, Eighemhenrio A, Kumolalo FO. Modified transanal repair of congenital H-type rectovestibular fistula: a technique to avoid recurrence. Afr J Paediatr Surg. (2013) 10:38. doi: 10.4103/0189-6725.109393

54. Ogundoyin O, Afuwape O, Olulana D, Lawal T. Anorectal malformation in an adult: a case report. Afr J Med Med Sci. (2013) 42:359-60.

55. Adamou H, Magagi IA, Habou O, Adakal O, Ganiou K, Amadou M. Acute mechanical intestinal obstruction in children at zinder national hospital, Niger: aetiologies and prognosis. Afr J Paediatr Surg. (2017) 14:49-52. doi: 10.4103/ajps.AJPS_96_16
56. Toobaie A, Emil S, Ozgediz D, Krishnaswami S, Poenaru D. Pediatric surgical capacity in Africa: current status and future needs. J Pediatr Surg. (2017) 52:843-8. doi: 10.1016/j.jpedsurg.2017.01.033

57. Chirdan LB, Ameh EA, Abantanga FA, Sidler D, Elhalaby EA. Challenges of training and delivery of pediatric surgical services in Africa. J Pediatr Surg. (2010) 45:610-8. doi: 10.1016/j.jpedsurg.2009.11.007

58. Vilanova-Sánchez A, Reck CA, Wood RJ, Mauriño CG, Gasior AC, Dyckes RE, et al. Impact on patient care of a multidisciplinary center specializing in colorectal and pelvic reconstruction. Front Surg. (2018) 5:68. doi: 10.3389/fsurg.2018.00068

59. Ameh EA, Adejuyigbe O, Nmadu PT. Pediatric surgery in Nigeria. J Pediatr Surg. (2006) 41:542-6. doi: 10.1016/j.jpedsurg.2005.11.053

60. Elhalaby EA, Uba FA, Borgstein ES, Rode H, Millar AJ. Training and practice of pediatric surgery in Africa: past, present, and future. Semin Pediatr Surg Elsevier. (2012) 21:103-10. doi: 10.1053/j.sempedsurg.2012.01.002

61. Dell A, Numanoglu A, Arnold M, Rode H. Paediatric surgeon density in South Africa. J Pediatr Surg. (2017) 53:2065-71. doi: 10.1016/j.jpedsurg. 2017.11.067

62. Olivieri C, Belay K, Coletta R, Retrosi G, Molle P, Calisti A. Preventing posterior sagittal anoplasty'cripples' in areas with limited medical resources: a few modifications to surgical approach in anorectal malformations. Afr J Paediatr Surg. (2012) 9:223. doi: 10.4103/0189-6725.104724

63. Shija J. Some observations on anorectal malformations in Zimbabwe. Central Afr J Med. (1986) 32:208-13.

64. Abdalla MS, Nour MA, El-Dessouky MS, El-Kholi ND. Posterior sagittal anorectoplasty for anorectal anomalies. Saudi Med J. (1991) 12:290-3.

65. Ntia I, Mungadi I, Agwu N. Management of anorectal malformation in children: a 10 year experience in Sokoto, Nigeria. Sahel Med J. (2007) 10:12831. doi: 10.4314/smj2.v10i4.12954

66. Peña A, Migotto-Krieger M, Levitt MA. Colostomy in anorectal malformations: a procedure with serious but preventable complications. J Pediatr Surg. (2006) 41:748-56. doi: 10.1016/j.jpedsurg.2005.12.021

67. Abdur-Rahman L, Shawyer A, Vizcarra R, Bailey K, Cameron B. Do geography and resources influence the need for colostomy in Hirschsprung's disease and anorectal malformations? A Canadian association of paediatric surgeons: Association of paediatric surgeons of Nigeria survey. Afr J Paediatr Surg. (2014) 11:150. doi: 10.4103/0189-6725.132813

68. Chirdan LB, Uba FA, Ameh EA, Mshelbwala PM. Colostomy for high anorectal malformation: an evaluation of morbidity and mortality in a developing country. Pediatr Surg Int. (2008) 24:407-10. doi: 10.1007/s00383-008-2114-Z

69. Lukong CS, Jabo BA, Mfuh AY. Colostomy in neonates under local anaesthesia: indications, technique and outcome. Afr J Paediatr Surg. (2012) 9:176. doi: 10.4103/0189-6725.99412

70. Youssef F, Arbash G, Puligandla PS, Baird RJ. Loop versus divided colostomy for the management of anorectal malformations: a systematic review and meta-analysis. J Pediatr Surg. (2017) 52:783-90. doi: 10.1016/j.jpedsurg.2017.01.044

71. Ozgediz D, Poenaru D. The burden of pediatric surgical conditions in low and middle income countries: a call to action. J Pediatr Surg. (2012) 47:2305-11. doi: 10.1016/j.jpedsurg.2012.09.030

72. Derbew M. Pediatric surgery in Eastern Africa: the unmet need. J Pediatr Surg. (2018) 54:21-6. doi: 10.1016/j.jpedsurg.2018.10.028

73. Yousef Y, Lee A, Ayele F, Poenaru D. Delayed access to care and unmet burden of pediatric surgical disease in resource-constrained African countries. J Pediatr Surg. (2018). doi: 10.1016/j.jpedsurg.2018.06.018. [Epub ahead of print].

74. Aiwanlehi E, Murphy O, Abraham A. Colostomy for anorectal malformation in a tertiary center in Nigeria. East Central Afr J Surg. (2016) 21:47-54. doi: 10.4314/ecajs.v21i2.7

75. Nour S, Beck J, Stringer M. Colostomy complications in infants and children. Ann R Coll Surg Engl. (1996) 78:526.

76. Patwardhan N, Kiely E, Drake D, Spitz L, Pierro A. Colostomy for anorectal anomalies: high incidence of complications. J Pediatr Surg. (2001) 36:795-8. doi: 10.1053/jpsu.2001.22963

77. Ekpemo SC, Eleweke N, Chapp-Jumbo A. Childhood Colostomy and Its Complications in Aba, Nigeria. Int J Clin Exp Med Sci. (2018) 4:32-4. doi: 10.11648/j.ijcems.20180403.11 
78. Osifo O, Osaigbovo E, Obeta E. Colostomy in children: indications and common problems in Benin City, Nigeria. Pak J Med Sci. (2008) 24:199.

79. OURO-BANG' Namaman AF, Kabore RAF, Zoumenou E, Gnassingbe K, and Chobli M. Anesthesia for children in Sub-Saharan Africa-a description of settings, common presenting conditions, techniques and outcomes. Pediatr Anesthes. (2009) 19:5-11. doi: 10.1111/j.1460-9592.2008.02838.x

80. Zoumenou E, Gbenou S, Assouto P, MAMAN A.F.O.B.N, Lokossou T, Hounnou G, et al. Pediatric anesthesia in developing countries: experience in the two main university hospitals of Benin in West Africa. Pediatr Anesthes. (2010) 20:741-7. doi: 10.1111/j.1460-9592.2010.03348.x

81. Chowdhary S, Chalapathi G, Narasimhan K, Samujh R, Mahajan J, Menon $\mathrm{P}$, et al. An audit of neonatal colostomy for high anorectal malformation: the developing world perspective. Pediatr Surg Int. (2004) 20:111-3. doi: 10.1007/s00383-003-1100-8

82. Faponle AF, Sowande OA, Adejuyigbe O. Anaesthesia for neonatal surgical emergencies in a semi-urban hospital, Nigeria. East Afr Med J. (2004) 81:56873.

83. Westgarth-Taylor C, Westgarth-Taylor T, Wood R, Levitt M. Imaging in anorectal malformations: what does the surgeon need to know? SA J Radiol. (2015) 19:a903. doi: 10.4102/sajr.v19i2.903

84. Riccabona M, Lobo ML, Ording-Muller LS, Thomas Augdal A, Fred Avni E, Blickman J, et al. European Society of Paediatric Radiology abdominal imaging task force recommendations in paediatric uroradiology, part IX: imaging in anorectal and cloacal malformation, imaging in childhood ovarian torsion, and efforts in standardising paediatric uroradiology terminology. Pediatr Radiol. (2017) 47:1369-80. doi: 10.1007/s00247-017-3837-6

85. Heij HA, Nievelstein RA, de Zwart I, Verbeeten BW, Valk J, Vos A. Abnormal anatomy of the lumbosacral region imaged by magnetic resonance in children with anorectal malformations. Arch Dis Child. (1996) 74:441-4. doi: 10.1136/adc.74.5.441

86. Madhusmita Ghasi RG, Mittal MK, Bagga D. Anorectal malformations: role of MRI in preoperative evaluation. Ind J Radiol Imag. (2018) 28:187-94. doi: 10.4103/ijri.IJRI_113_17

87. Ekwunife OH, Umeh EO, Ugwu JO, Ebubedike UR, Okoli CC, Modekwe VI, et al. Comparison of trans-perineal ultrasound-guided pressure augmented saline colostomy distension study and conventional contrast radiographic colostography in children with anorectal malformation. Afr J Paediatr Surg. (2016) 13:26. doi: 10.4103/0189-6725.181703

88. Halawa NAA, Abdelgawad AE, Elhalaby EA. Current management of anorectal malformation in Egypt: a survey of members of the Egyptian pediatric surgical association. Ann Pediatr Surg. (2017) 13:203-6. doi: 10.1097/01.XPS.0000520192.70388.2c

89. Osifo O, Osagie T, Udefiagbon E. Outcome of primary posterior sagittal anorectoplasty of high anorectal malformation in well selected neonates. Nigerian J Clin Prac. (2014) 17:1-5. doi: 10.4103/1119-3077.122821
90. Osagie T, Aisien E, Osifo O. Outcomes of posterior sagittal anorectoplasty for high anorectal malformation in benin city, Nigeria. J West Afr College Surg. (2016) 6:16.

91. Elhalaby EA. Primary repair of high and intermediate anorectal malformations in the neonates. Ann Pediatr Surg. (2006) 2:117-22.

92. Adeniran J, Abdur-Rahman L. One-stage correction of intermediate imperforate anus in males. Pediatr Surg Int. (2005) 21:88-90. doi: 10.1007/s00383-004-1211-x

93. Adeniran J. One-stage correction of imperforate anus and rectovestibular fistula in girls: preliminary results. J Pediatr Surg. (2002) 37:16-9. doi: 10.1053/jpsu.2002.32927

94. Elbatarny A, Elafifi M, Ismail K, Metwally M, Hashish A, Elmahalawy M, et al. Evaluation of one-stage posterior sagittal anorectoplasty for the repair of high and intermediate anorectal malformations. Ann Pediatr Surg. (2009) 5:36-45.

95. Peña A, Devries PA. Posterior sagittal anorectoplasty: important technical considerations and new applications. J Pediatr Surg. (1982) 17:796-811. doi: 10.1016/S0022-3468(82)80448-X

96. Abdelmaksoud SA, El-Saied AW, Dessouky NM, Aly KA. Evaluation of laparoscopic-assisted anorectoplasty for the management of intermediate and high anorectal malformations in boys: mansoura experience. Ann Pediatr Surg. (2018) 14:72-7. doi: 10.1097/01.XPS.0000525976. 79181

97. De Vos C, Arnold M, Sidler D, Moore S. A comparison of laparoscopicassisted (LAARP) and posterior sagittal (PSARP) anorectoplasty in the outcome of intermediate and high anorectal malformations. South Afr J Surg. (2011)49:39-43

98. Calisti A, Belay K, Mazzoni G, Fiocca G, Retrosi G, Olivieri C. Promoting major pediatric surgical care in a low-income country: a 4-year experience in Eritrea. World J Surg. (2011) 35:760-6. doi: 10.1007/s00268011-0992-z

99. Lawal TA, Reck CA, Wood RJ, Lane VA, Gasior A, Levitt MA. Use of a heineke-Mikulicz like stricturoplasty for intractable skin level anal strictures following anoplasty in children with anorectal malformations. J Pediatr Surg. (2016) 51:1743-5. doi: 10.1016/j.jpedsurg.2016.07.013

Conflict of Interest Statement: The author declares that the research was conducted in the absence of any commercial or financial relationships that could be construed as a potential conflict of interest.

Copyright (c) 2019 Lawal. This is an open-access article distributed under the terms of the Creative Commons Attribution License (CC BY). The use, distribution or reproduction in other forums is permitted, provided the original author(s) and the copyright owner(s) are credited and that the original publication in this journal is cited, in accordance with accepted academic practice. No use, distribution or reproduction is permitted which does not comply with these terms. 